\title{
Optimum Design of Impulse Ventilation System in Underground Car Parking Basement by Using CFD Simulation
}

\section{Lakamana Umamaheswararao*}

Design and Development Engineer, Saudi Fan Industries, KSA

\begin{abstract}
The most significant development in car park ventilation design has been the introduction of Impulse Ventilation. It is an innovative alternative to traditional systems and provides a number of significant benefits. The ventilation of car parks is essential for removing vehicle exhausts Fumes and smoke in case of fire containing harmful pollutants. So design of impulse systems is usually proven by use of CFD (Computational Fluid Dynamic) analysis. In this study considered one of the car parking basement which is in Riyadh, Saudi Arabia and study was conducted by using ANSYS-Fluent. The field study was carried to collect the actual data of boundary conditions for CFD simulation. In this study, two Cases of jet fan smoke ventilation systems were considered, one has 8 jet fans according to the customer and another one has 11 jet fans which positions were changed accordingly. Base on the comparison of simulation data, ventilation system with 11 jet fans can help to improve the evacuation of fumes in the car parking area and it is also observed that the concentration of $\mathrm{CO}$ minimized within 15 minutes.
\end{abstract}

Keywords: Impulse ventilation; CFD; AMC hospital; Jet fans

\section{Introduction}

The most significant development in car park ventilation design has been the introduction of Impulse Ventilation. It is an innovative alternative to traditional systems and provides a number of significant benefits. An Impulse Ventilation System is based on a number of small high velocity jet fans that either replace traditional distribution ductwork in closed car parks or increase cross-flow ventilation in open car parks. The ventilation of car parks is essential for removing vehicle exhaust fumes containing harmful pollutants. Some of these pollutants include Carbon Monoxide (CO), Nitrous Oxides (NOX), Sulphur Dioxide $\left(\mathrm{SO}_{2}\right)$ and heavy metal compounds.

Ventilation systems for car parks and service areas are required to achieve two objectives. Firstly, when the car park or service area is in general use, it is important that the exhaust gases produced by vehicles are effectively removed and that there are no pockets of stagnant air. Secondly, in the event of a fire, assistance needs to be given to the Fire Service to clear smoke from the car park during and after the fire. Therefore, it is important to study the design of ventilation system in the enclosed car parking areas.

In early age of construction, the most of building related issues such as ventilation analysis, wind loading, wind environment etc. were conducted by the wind tunnel tests, but today all these test can be done effectively with CFD technique [1]. CFD technique can resolve all above mentioned issues in very short time period and it is very economical as well as strong approach than the older one (experimental).

\section{Methods}

In this study impulse ventilation system was designed according to the standards, the basic requirements that ventilation system will provide 6 air changes per hour $(\mathrm{ACH})$ for general ventilation on all levels and $10 \mathrm{ACH}$ on the fire floor in the event of a fire [2]. The system should be capable of operating at temperatures of up to $300^{\circ} \mathrm{C}$ for 60 minutes and ductwork and fixings should be made from materials that have a melting point above $800^{\circ} \mathrm{C}[2]$. The system should have at least 2 extract fans, each providing $50 \%$ of the extract, with a secondary power supply to operate in the event of a mains power failure [3]. Extract points should be designed with $50 \%$ of the outlets at high level and 50\% at low level [3].
The CFD model accounted for columns, beams, internal walls and other construction elements which could form an obstruction to the air flow as shown in Figure 1 and total car parking area is $3500 \mathrm{~m}^{2}$. The ventilation system should inject an even amount of air across the car park in order to evacuate the smoke plume downstream of the fire and the source of the fire is car as mentioned in Figure 1. Computational approach carried in such a way that steady state CFD analysis on a car parking area with mass and energy equation. k- $\varepsilon$ two-equation turbulence model was used for modelling turbulent flow. After steady state analysis performed species analysis in transient condition. All equations are activated and ran parallel with species equation. Appropriate species mass fraction was entered as per client input data. Transient simulation was performed for 15 minutes. Species Transport approach was used for modelling smoke. Energy equation and S2S radiation model were solved to account for the heat release.

Here CFD simulation was performed on the design of car parking basement of AMC Hospital, Riyadh, Saudi Arabia. CFD study for car park basement to determine the optimal locations and the performance of the fans in evacuating the smoke in the event of a fire. So here the study of CFD was performed in two Cases as follows:

Case I: Location and number of fans according to the customer are 8 Jet fans as shown in Figure 2.

Case II: Location of the fans based on the results obtained from Case 1 CFD simulation results and increased number fans to 11 as shown in Figure 3.

*Corresponding author: Lakamana Umamaheswararao, Design and Development Engineer, Saudi Fan Industries, KSA, Tel: 966138121282; E-mail: um@refhouse.com

Received November 15, 2017; Accepted November 27, 2017; Published December 04, 2017

Citation: Umamaheswararao L (2017) Optimum Design of Impulse Ventilation System in Underground Car Parking Basement by Using CFD Simulation. Ind Eng Manage 6: 238. doi:10.4172/2169-0316.1000238

Copyright: (c) 2017 Umamaheswararao L. This is an open-access article distributed under the terms of the Creative Commons Attribution License, which permits unrestricted use, distribution, and reproduction in any medium, provided the original author and source are credited. 
Citation: Umamaheswararao L (2017) Optimum Design of Impulse Ventilation System in Underground Car Parking Basement by Using CFD Simulation. Ind Eng Manage 6: 238. doi:10.4172/2169-0316.1000238

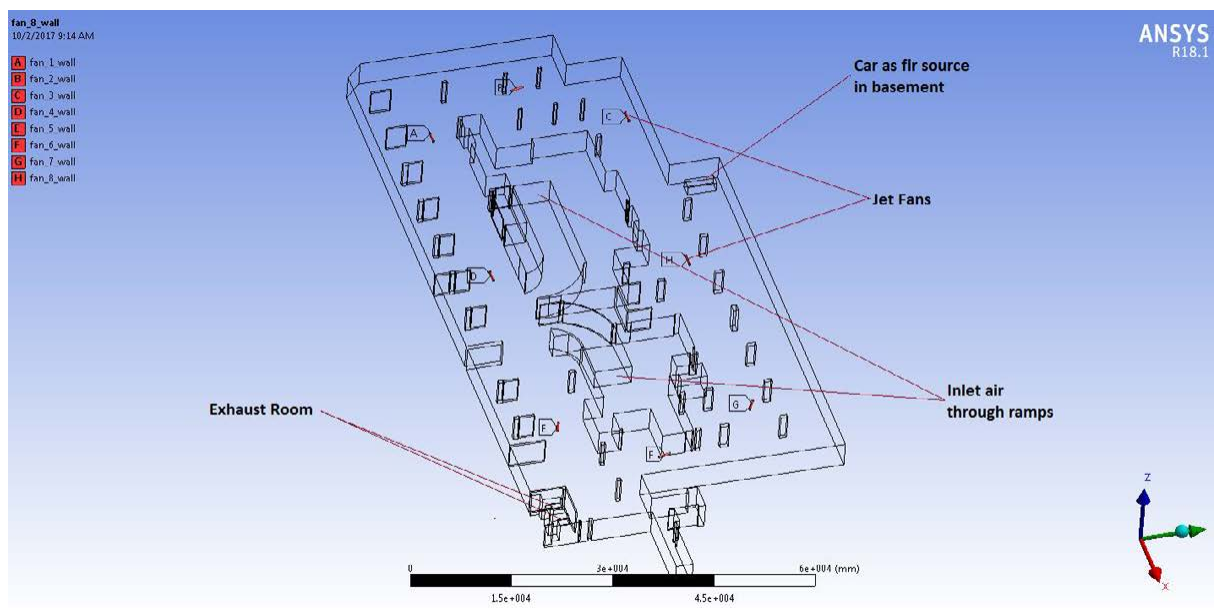

Figure 1: 3D model of Car Parking area.

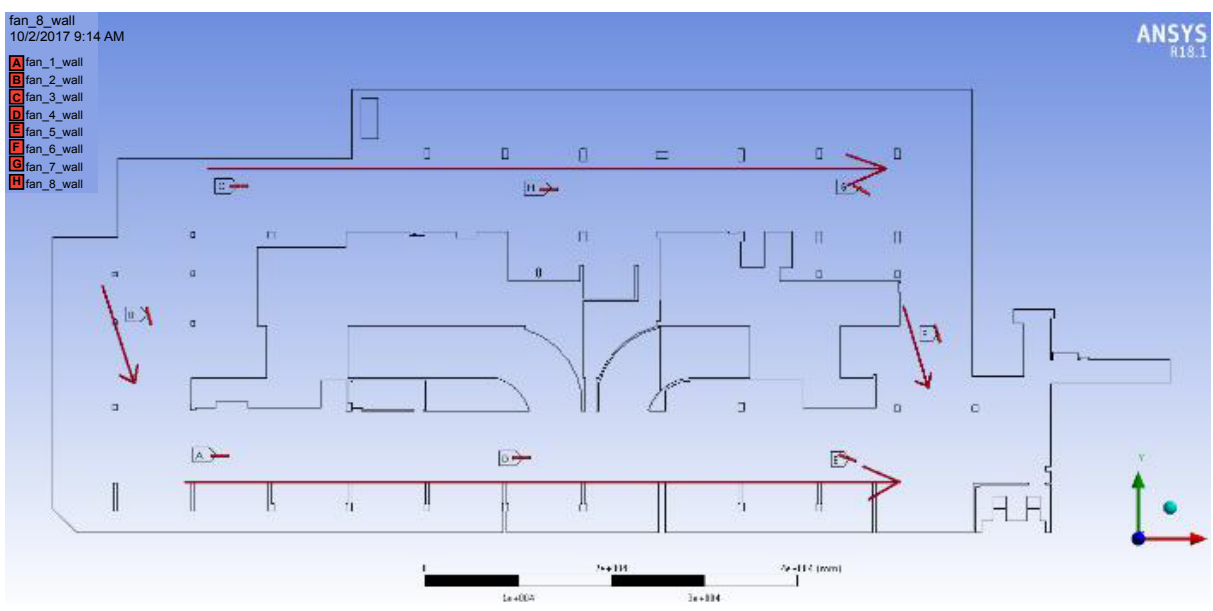

Figure 2: Flow direction of 8 jet fans.

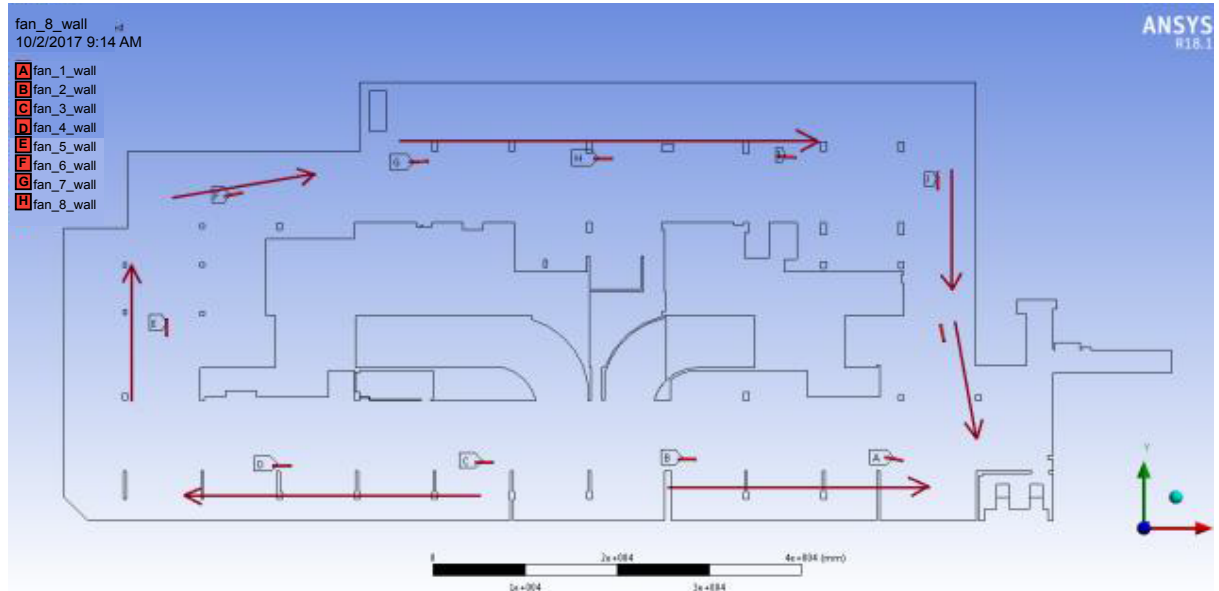

Figure 3: Flow direction of 11 jet fans.

\section{Boundary Conditions}

- Air inlet-pressure inlet with $0.23 \mathrm{O}_{2}$ mass fraction.
- Exhaust fans - Mass flow out with $27.56 \mathrm{~kg} / \mathrm{s}$ which is equivalent to $22500 \mathrm{l} / \mathrm{s}$. 
Citation: Umamaheswararao L (2017) Optimum Design of Impulse Ventilation System in Underground Car Parking Basement by Using CFD Simulation. Ind Eng Manage 6: 238. doi:10.4172/2169-0316.1000238

Page 3 of 6

- Mass flow rate- mass flow with $0.1 \mathrm{~kg}$ and $10 \% \mathrm{CO}$ in air mixture having $900 \mathrm{~K}$ temperature were produced by the fire explosion [4].

- Jet fans with $41 \mathrm{~N}$ thrust and temperature range up to $+570 \mathrm{~K}$ [5].

\section{Results}

The complete simulation of the analysis is performed in two phases.

\section{Phase-I}

Performed steady state CFD analysis on a car parking area with mass, turbulence and energy equation. The effect of species flow is not considered as of now. This could be included in next phase. Understand flow profile and re-circulation zones in parking area. After the 1000 iterations of steady state analysis observed the flow pattern in both the cases as shown in Figure 4.

\section{Phase-II}

Performed transient CFD analysis with species analysis. All equations are activated and ran parallel with species equation. Transient simulation was performed for 15 minutes and found the temperature nearer jet fans is approximately $560 \mathrm{~K}$, so it is under allowable temperature by manufacturer. Observed the temperature after 60 seconds fire exposure for case I is distributing left side area in the car parking and it is away from the exhaust room but in Case II the distribution of temperature is minimum as shown in Figure 5.

Here the smoke will be spreads over the car parking area after fire explosion and Carbon monoxide (CO) exposure accounts for the majority of total fire fatalities. Exposure to $\mathrm{CO}$ results in car oxyhemoglobin $(\mathrm{COHb})$ uptake in the blood, which results in decreased oxygen-carrying capacity of the blood [6]. The ventilation designed to limit the concentration of carbon monoxide to not more than 50 parts per million or $0.005 \%$ averaged over an eight-hour period and peak concentrations, such as by ramps and exits, not to go above 100 parts per million for periods not exceeding 15 minutes [7-10]. So here evacuation of $\mathrm{CO}$ is taken as main criteria and simulated for 15 minutes and observed the results as follows (Figures 6-9).

At the time after 60 seconds CO was distributed in Case I scenario because flow direction of jet fans and CO concentration is reached 100 ppm after 450 seconds. In Case II the concentration of CO after 450
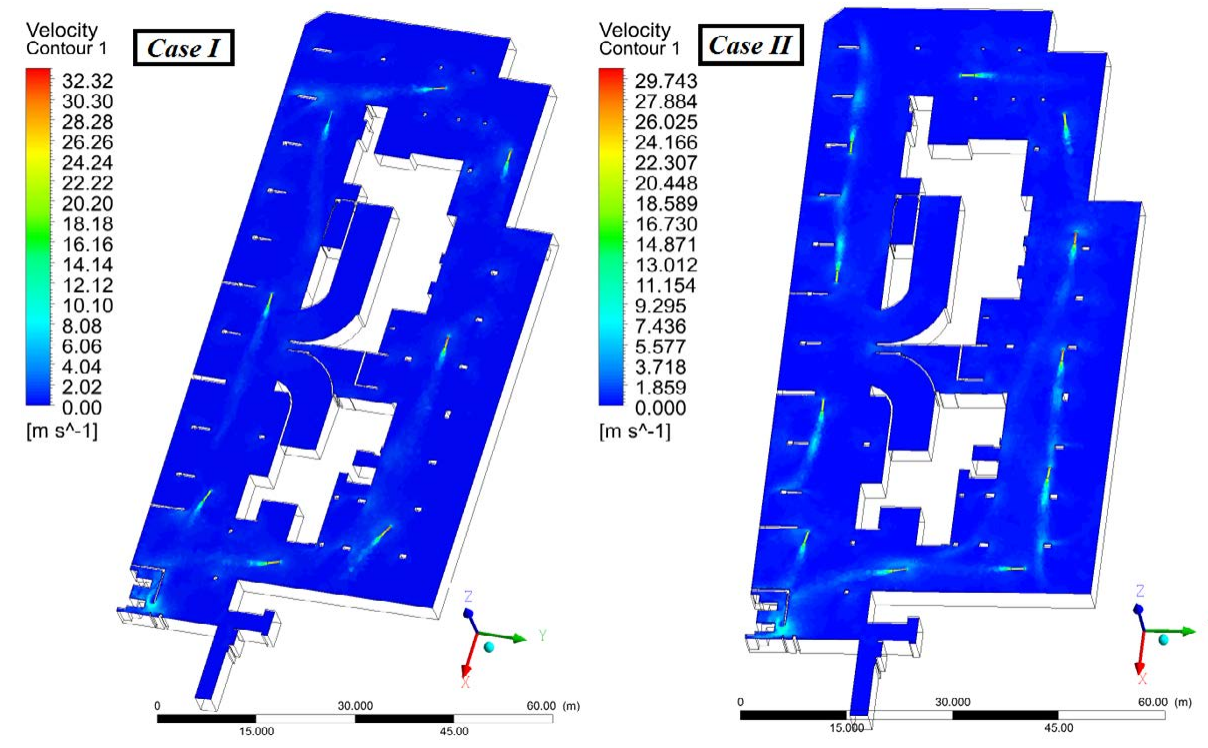

Figure 4: Air flow of jet fans in car parking area.
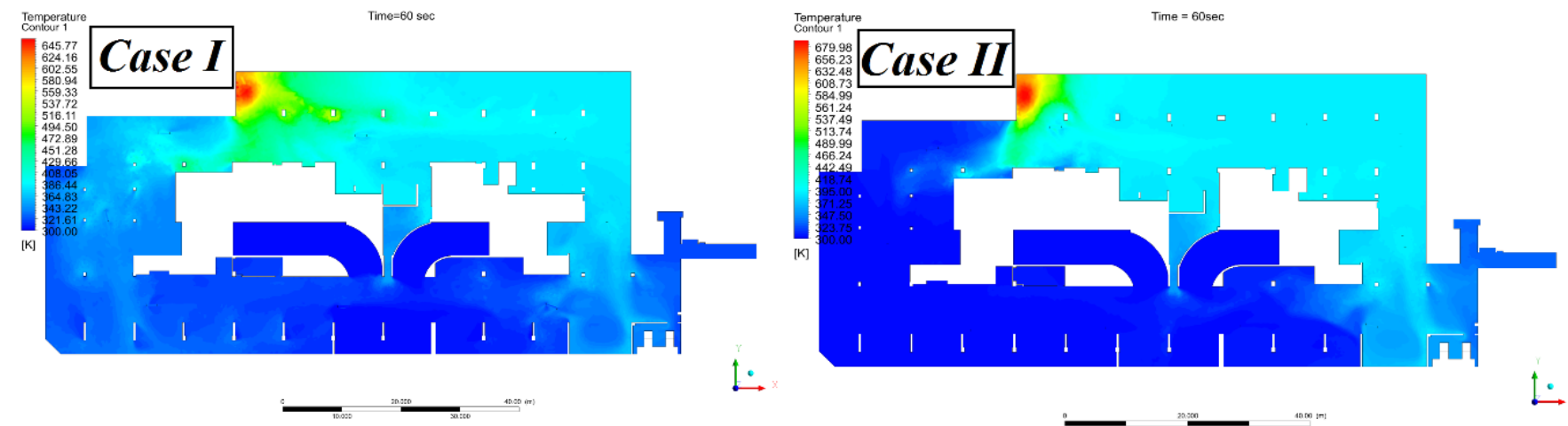

Figure 5: Temperature distribution in car parking area after 60 seconds fire. 
Citation: Umamaheswararao L (2017) Optimum Design of Impulse Ventilation System in Underground Car Parking Basement by Using CFD Simulation. Ind Eng Manage 6: 238. doi:10.4172/2169-0316.1000238
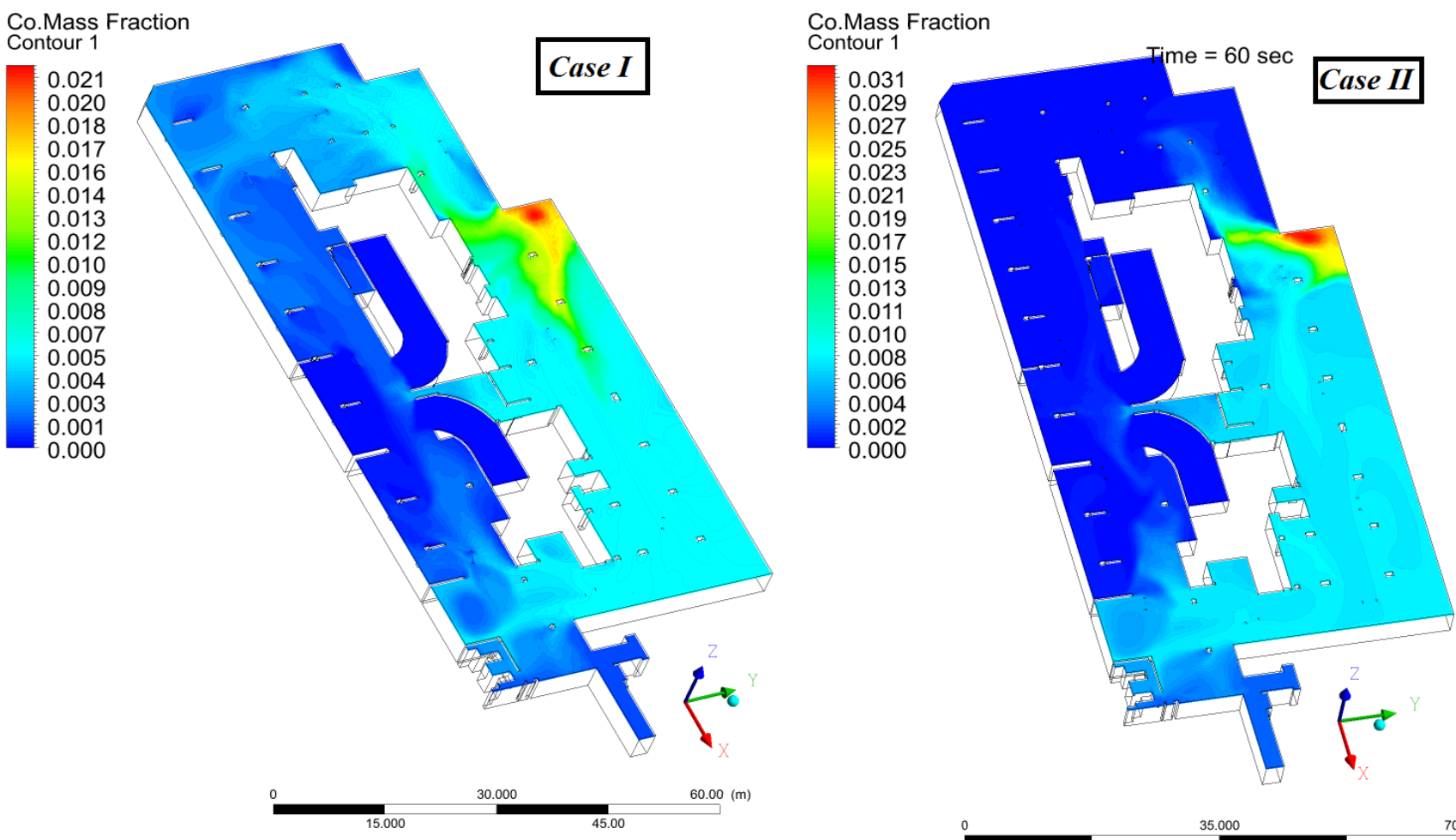

Figure 6: CO mass concentration after 60 seconds of fire.
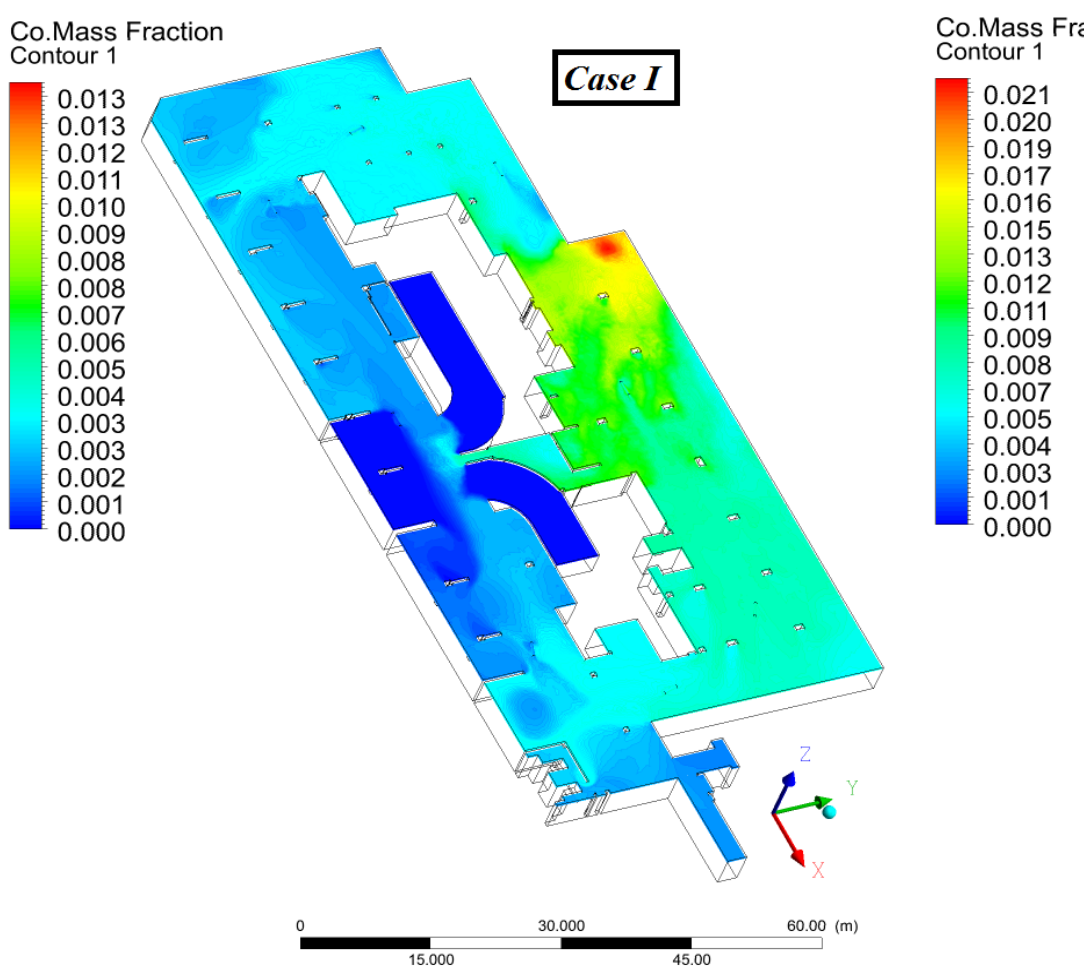

Figure 7: CO mass concentration after 450 seconds of fire. 
Citation: Umamaheswararao L (2017) Optimum Design of Impulse Ventilation System in Underground Car Parking Basement by Using CFD Simulation. Ind Eng Manage 6: 238. doi:10.4172/2169-0316.1000238
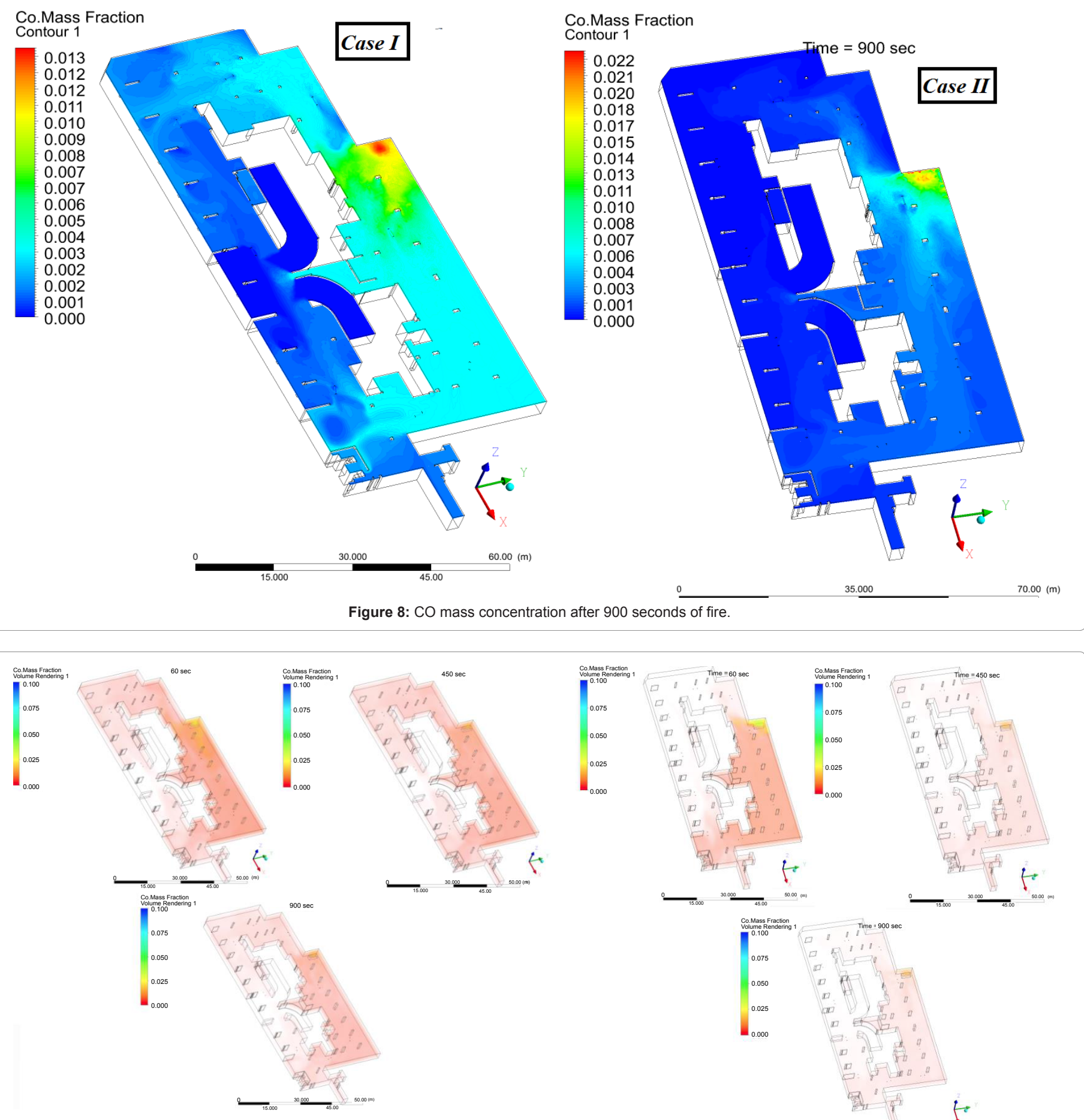

Case I

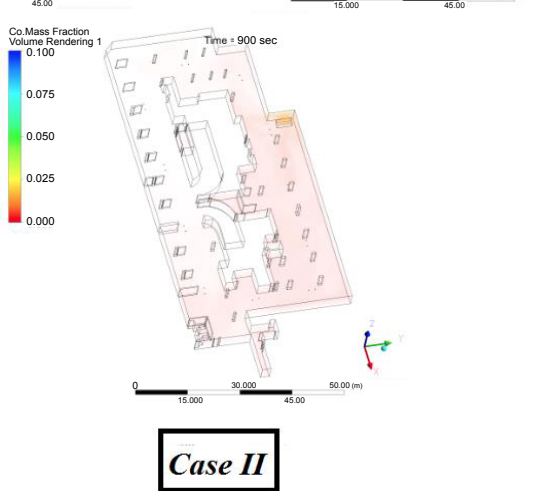

Figure 9: CO Mass volume comparison between both cases.

seconds is less than $50 \mathrm{ppm}$ in the basement except nearer to fire zone. So as per the simulation results it is observed that $\mathrm{CO}$ concentration still remains after 900 seconds in Case I scenario but in Case II almost $\mathrm{CO}$ concentration evacuated from the car parking area [11-15].

\section{Conclusions}

In this study CFD can provide detailed prediction of air movement, temperature and smoke density throughout the car park. This level of 
Citation: Umamaheswararao L (2017) Optimum Design of Impulse Ventilation System in Underground Car Parking Basement by Using CFD Simulation. Ind Eng Manage 6: 238. doi:10.4172/2169-0316.1000238

detail cannot be provided by any other means. For this simulation real time boundary conditions taken from the AMC Hospital construction company and made discussions with the customer as per their requirement. According to that, recommended the proper design for the ventilation system. As per the customer point of view they required only 8 Jet fans and locations as per Case I but after the CFD analysis results not satisfactory. So we (Saudi Fan Industries) recommended 11 fans and optimum locations for smoke ventilation system. Obtained the less than $50 \mathrm{ppm}$ of $\mathrm{CO}$ concentration nearer to fire location and makes visibility for fire frightening. So CFD analysis is a good method to demonstrate to approving authorities that the system is likely to perform satisfactorily.

\section{Acknowledgements}

Supported by Saudi Fan Industries, Saudi Arabia and C \& P Contracting Company, Saudi Arabia.

\section{References}

1. Gomaa SM, Khalil EE, Fouad M, Medhat A (2015) Ventilation System Design for Underground Car Park. Open Journal of Technology \& Engineering Disciplines (OJTED) 1: 30-41

2. Ladeinde F, Nearon MD (1997) CFD application in the HVAC \& R industry. ASHRAE Journal 39: 44-48.

3. British Standards (2006) Components for smoke and heat control systems - Part 7: Code of practice on functional recommendations and calculation methods for smoke and heat control systems for covered car parks. ICS 13.220.20. BS 7346-7: 2006.
4. The Building Regulations 2000. Approved Document F

5. Klote JH, Milke JA, Turnbull PG, Kashef A, Ferreira MJ (2012) Hand book of smoke control engineering. ASHRAE Journal, ISBN 978-1-936504-24-42012.

6. Smoke extract and Jet fans, SMK.F/JET.F Series, Catalogue \#SF-03

7. Lu S, Wang YH, Zhang RF, Zhang HP (2011) Numerical Study on Impulse Ventilation for Smoke Control in an Underground Car Park. Procedia Engineering 11: 369-378.

8. Van De Giessen BJM, Penders SHA, Loomans MGLC, Rutten PGS, Hensen JLM (2011) Modelling and Simulation of a Jet Fan for Controlled Air Flow in Large Enclosures. Environmental Modelling \& Software 26: 191-200.

9. EFAFLU (2010) Jet Fans Catalogue. EFAFLU Bombas e Ventiladores.

10. Colt (2011) Ventilation Systems for Car Parks and Service Areas. Colt International Ltd.

11. Jojo SML, Chow WK (2003) Numerical Studies on Performance Evaluation of Tunnel Ventilation Safety Systems. Tunneling and Underground Space Technology 18: 435-452.

12. Vega MG, Dia KMA, Oro JMF, Tajadura RB, Morros CS (2008) Numerica 3D Simulation of a Longitudinal Ventilation System: Memorial Tunnel Case. Tunneling and Underground Space Technology 23: 539-551.

13. Karim VM, Bart M (2008) Application of RANS and LES Field Simulations to Predict the Critical Ventilation Velocity in Longitudinally Ventilated Horizontal Tunnels. Fire Safety Journal 43: 598-609.

14. Viegas JC (2006) The Use of Jet Fans to Improve the Air Quality in Underground Car Parks. In Proceedings of Healthy Buildings 2006 Conference, Lisbon.

15. Neidy VG (2009) Numerical Simulation of a Flow Induced by a Fire in a Covered Car Park. Instituto Superior Tecnico, Portugal. 